This item was submitted to Loughborough's Research Repository by the author.

Items in Figshare are protected by copyright, with all rights reserved, unless otherwise indicated.

\title{
smaRTI—A cyber-physical intelligent container for industry 4.0 manufacturing
}

PLEASE CITE THE PUBLISHED VERSION

https://doi.org/10.1016/j.jmsy.2019.04.011

\section{PUBLISHER}

(C) The Society of Manufacturing Engineers. Published by Elsevier Ltd

\section{VERSION}

AM (Accepted Manuscript)

\section{PUBLISHER STATEMENT}

This paper was accepted for publication in the journal Journal of Manufacturing Systems and the definitive published version is available at https://doi.org/10.1016/j.jmsy.2019.04.011.

\section{LICENCE}

CC BY-NC-ND 4.0

\section{REPOSITORY RECORD}

Neal, Aaron D., Richard Sharpe, Paul Conway, and Andrew A. West. 2019. "Smarti-a Cyber-physical Intelligent Container for Industry 4.0 Manufacturing". Loughborough University.

https://hdl.handle.net/2134/37894. 
Title: smaRTI - A Cyber-Physical Intelligent Container for Industry 4.0 Manufacturing

Authors: Aaron Neal, Richard Sharpe, Paul Conway, Andrew West

Abstract:

Cyber-Physical Systems (CPSs) are becoming a significant research focus resulting from advancements in technologies such as the Internet of Things (IOT), Cloud Manufacturing and Intelligent Products. Successful deployment of CPSs has the potential to provide a step change in manufacturing efficiency, flexibility and production yield as envisaged by the fourth industrial revolution or Industry 4.0 paradigm. The realisation of intelligent products and services is in the provisioning of predictive, risk preventative and high-performance manufacturing systems. As part of these manufacturing systems, Returnable Transit Items (RTIs) play a critical role in provisioning robust and efficient means of component (e.g. Work in Progress and finished items) protection and logistics. The research outlined in this paper details how a Returnable Transit Item (RTI) can become an integral part of the Industrie 4.0 vision as an intelligent container that can interact with components, machines and other cyber-physical manufacturing services. This paper discusses a CPS reference architecture for the integration of intelligent containers and presents a hardware and software proof of concept solution suitable for industrial deployments. The paper concludes with feasibility studies utilising the intelligent container for context determination services including the identification of intelligent components and monitoring of logistical handling process (i.e. the detection of collisions, lifting and turns).

Keywords: Industrie 4.0, Cyber-Physical Systems, Intelligent Products, Returnable Transit Items, Intelligent Container

\section{Introduction}

The concept of an item that is used for the transportation of goods which is re-usable has been identified under many names such as, Returnable Logistical Packaging [1]; Returnable Containers [2]; Distribution Items [3], Reusable Transport Items [4] and Returnable Transit Items [5]. For clarity, this paper will use the term Returnable Transit Item (RTI). RTIs are a tool used within manufacturing for aggregating many components into a single entity that improves logistical efficiency and reduces costs [6]. This is achieved through maximising the use of space, more efficient handling and the reduction of one-way packaging [7]. RTIs also provide an effective role in component protection, not least from physical damage but also from environmental conditions such as grime, dust and moisture and can be exposed to harsh environments that can lead them to become damaged whilst still protecting the components [8]. With reports of RTI fleet sizes being reduced $10 \%$ annually through damage [9] and a further $10 \%$ through RTI misplacement (lost) and shrinkage (i.e. not-returned or stolen) [10], [11], there are significant operational challenges to be overcome. These operational challenges include determining RTI fleet size [12], [13], identifying excessive customer holding time [14], analysing the effect of RTI leakage and damages [15] and understanding the optimal purchasing policies [16]. However, without knowledge of how RTIs flow through the supply chain these challenges become difficult if not impossible to address, to maintain an efficient RTI pool there is a significant challenge in ensuring that adequate RTI monitoring systems are in place [8]. It is evident that with the introduction of contracts, incentives, penalties and maintenance operations, there is a requirement to ensure that effective monitoring and tracking of RTIs is achieved. This will ensure that there are no disagreements over the validity of any decisions on responsibility in response to issues such as RTI losses and damages [8], [9]. To address these issues Radio Frequency Identification (RFID) monitoring systems have been implemented for RTI monitoring [7-9]. Generally, these systems do not provide the ability for unique component traceability and monitoring. With Industrie 4.0 being proposed as the next industrial revolution [11], where the ubiquitous nature of communication technologies is utilised to link manufacturing operations, intelligent products and the human workforce to provide next generation manufacturing systems [12], there is a need for a greater integration of product, processes and operators within the manufacturing domain. To support the Industrie 4.0 vision, the development of intelligent products and services are a way of distributing the execution of product specific tasks such as determining product context [13], interaction between other smart products, environments and machines [14], as well as being able to store data in a product centric model at all phases of its lifecycle [12]. This research is focused on the application of an intelligent RTI or container, which has knowledge of its constituent parts and can make decisions not only for itself, but on behalf of the products it holds [16]. This paper looks at the intelligent RTI concept for component traceability within the automotive domain and presents a hardware and software platform, known as 
smaRTI (smart Returnable Transit Item), that provides a foundation for intelligent container research, development and implementation.

\section{Intelligent Products}

There is a growing trend in the integration between the physical and digital worlds with real-time links required between the digital model of a facility and the physical machines, products and processes within it. By developing these links it has been suggested that there are advantages in the availability of product information [17], being able to track unique products [18], improve operational control through dynamic decision making [19] and an improvement to inventory monitoring and control [20]. Intelligent products align with the strive towards a product centric supply chain that meets the operational demands of high level product customisation and complex supply chains found within Cyber Physical Systems (CPSs) [21]-[23].

Many definitions of an intelligent product have been published such as by McFarlane et al. [24], Ventä [25] and Meyer et al. [26] whose definition is utilised within this research. Meyer et al. [26] describe the functionality of an intelligent container as an intelligent product that "not only manages information, notifications and/or decisions about itself, it is also aware of the components that it is made of and may act as a proxy device for them. If the intelligent container is disassembled or parts are removed or replaced, the parts may be able to continue as intelligent items or containers by themselves." Examples presented by the authors are of an intelligent vehicle, in which both the engine and shell were independent intelligent products interacting with one another and a "smart shelf" that can monitor and notify on stock levels. In these examples the intelligent products were the vehicle and the engine or the shelf and its products. For this research, the equivalent analogy is an intelligent RTI and its constituent (intelligent) components, i.e. intelligent cylinder heads, cylinder blocks or crankshafts. Within this context, an intelligent product is defined as a physical and information-based representation that possesses a unique identity, communicates with its environment, stores data about itself, utilises an information model of itself and is capable of participating or making decisions [15].

Meyer et al. [26] additionally present a classification model for describing intelligent products taking into consideration the differing intelligent product definitions and presented three primary features of intelligent products: the level of intelligence (information handling to decision making), the location of intelligence (intelligent at the object or within the network) and the aggregation of intelligence (intelligent item or intelligent container). Figure 1 presents two example characterisations, the intelligent container proposed within this paper (left) and a single RFID tagged product (right).

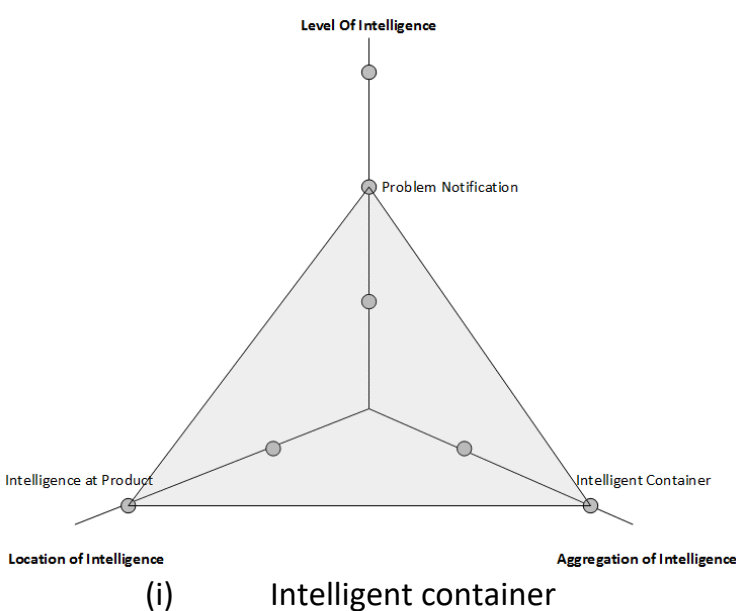

(i) Intelligent container

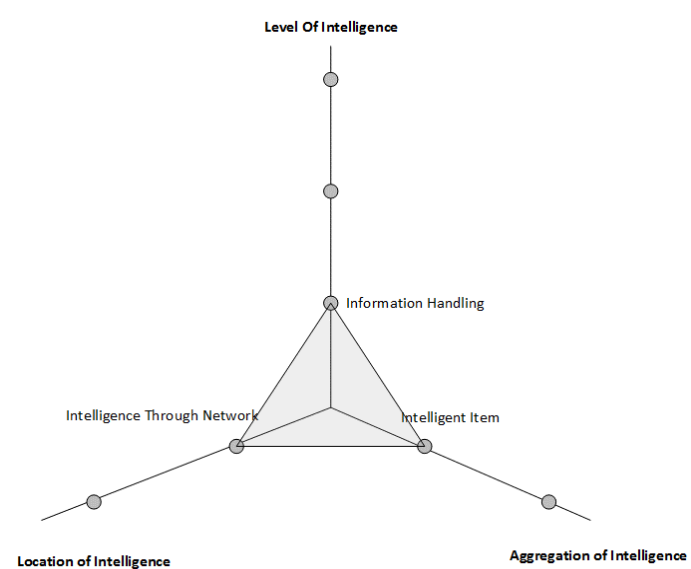

(ii) RFID tagged item

Figure 1 - Product intelligence characterisation adapted from [26] representing an intelligent container (left) and a single RFID tagged product (right) 


\subsection{Intelligent products in the supply chain}

Academic research papers and commercial offerings related to this research reviewed with regards to their relevance in adding intelligence to an RTI. The areas of comparison were (i) mobile - is the container mobile, (ii) - identifies constituent items - does the container uniquely identify the items it contains, (iii) self-decisions - does the container make decisions about its own destiny, (iv) part decisions - does the container make decisions on behalf of the items it contains and (v) state of research - to what level is the research or product deployed. The comparison has been shown in Table 1.

Table 1 - Comparison of reviewed literature

\begin{tabular}{|c|c|c|c|c|c|c|c|c|}
\hline & \multicolumn{5}{|c|}{ Academic } & \multicolumn{3}{|c|}{ Commercial } \\
\hline Name & $\begin{array}{l}\text { Smart Shelf } \\
\text { [27] }\end{array}$ & \begin{tabular}{|l} 
Networked \\
Containers \\
{$[28]$}
\end{tabular} & \begin{tabular}{|l|} 
Cargo \\
Monitoring \\
[29]
\end{tabular} & $\begin{array}{l}\text { Perishable } \\
\text { food in the } \\
\text { supply chain } \\
\text { [30] }\end{array}$ & \begin{tabular}{|l|} 
Intelligent \\
container [31]
\end{tabular} & $\begin{array}{l}\text { Remote } \\
\text { Container } \\
\text { Monitoring } \\
{[32]}\end{array}$ & $\begin{array}{l}\text { Forklift } \\
\text { monitoring } \\
{[33],[34]}\end{array}$ & $\begin{array}{l}\text { RTI } \\
\text { Monitoring } \\
{[35],[36]}\end{array}$ \\
\hline Description & \begin{tabular}{|l|} 
A shelf inside \\
a 'smart \\
warehouse' \\
that knows \\
what has been \\
picked and \\
where it goes \\
to allow \\
flexibility in \\
locations
\end{tabular} & \begin{tabular}{|l} 
Intelligent \\
networked \\
containers \\
that monitor \\
security and \\
identify \\
products \\
being loaded \\
in and out
\end{tabular} & $\begin{array}{l}\text { A 'smart } \\
\text { container' } \\
\text { which allows } \\
\text { remote } \\
\text { monitoring of } \\
\text { container } \\
\text { status } \\
\text { (temperature } \\
\text { and security), } \\
\text { optional } \\
\text { sensors to } \\
\text { identify } \\
\text { products } \\
\text { inside }\end{array}$ & $\begin{array}{l}\text { A crate with } \\
\text { 'smart } \\
\text { logistics' unit } \\
\text { to manage } \\
\text { perishable } \\
\text { food in the } \\
\text { supply chain }\end{array}$ & $\begin{array}{l}\text { Monitoring of } \\
\text { food in the } \\
\text { cold supply } \\
\text { chain }\end{array}$ & $\begin{array}{l}\text { Maersk } \\
\text { refrigerated } \\
\text { shipping } \\
\text { containers are } \\
\text { able to } \\
\text { communicate } \\
\text { to Maersk } \\
\text { ships, to } \\
\text { satellites and } \\
\text { back to } \\
\text { servers where } \\
\text { the status can } \\
\text { be remotely } \\
\text { monitored. }\end{array}$ & $\begin{array}{l}\text { Zeno Track * - } \\
\text { owned by } \\
\text { Bosch } \\
\text { Driver } \\
\text { assistance } \\
\text { system of } \\
\text { monitored } \\
\text { forklifts with } \\
\text { locations and } \\
\text { status } \\
\text { including } \\
\text { identification } \\
\text { of pallets. }\end{array}$ & $\begin{array}{l}\text { Systems such } \\
\text { as Vero and } \\
\text { TrackX exist to } \\
\text { monitor RTIs } \\
\text { in factories } \\
\text { these are } \\
\text { asset } \\
\text { monitoring / } \\
\text { management } \\
\text { solutions } \\
\text { where RTIs } \\
\text { are applied } \\
\text { with a } \\
\text { readable UID }\end{array}$ \\
\hline Mobile & $x$ & $\checkmark$ & $\checkmark$ & $\checkmark$ & $\checkmark$ & $\checkmark$ & $\checkmark$ & $\checkmark$ \\
\hline $\begin{array}{c}\text { Identifies } \\
\text { Constituent } \\
\text { parts }\end{array}$ & $\begin{array}{l}\checkmark \text { - RFID- } \\
\text { tagged items }\end{array}$ & $\begin{array}{l}\checkmark \text { - RFID- } \\
\text { tagged items }\end{array}$ & $\begin{array}{c}\checkmark-\text { not } \\
\text { specified }\end{array}$ & $\mathrm{x}$ & $\begin{array}{c}\checkmark \text { - RFID- } \\
\text { tagged } \\
\text { goods/pallets }\end{array}$ & $x$ & $\begin{array}{c}\checkmark \text { - could } \\
\text { identify } \\
\text { tagged pallets }\end{array}$ & $x$ \\
\hline $\begin{array}{c}\text { Self- } \\
\text { Decisions }\end{array}$ & $\begin{array}{c}\checkmark \text { - item stock } \\
\text { ordering }\end{array}$ & $\begin{array}{l}\checkmark \text { - intrusion } \\
\text { detection }\end{array}$ & $\begin{array}{l}\checkmark \text { - intrusion } \\
\text { detection }\end{array}$ & $\begin{array}{c}\text { ? - mentions } \\
\text { operational } \\
\text { decision } \\
\text { making but } \\
\text { does not } \\
\text { specify }\end{array}$ & $\begin{array}{l}\checkmark \text { - decides if } \\
\text { needs to } \\
\text { sending } \\
\text { warning } \\
\text { messages }\end{array}$ & $\begin{array}{l}\checkmark \text { - can notify } \\
\text { Maersk } \\
\text { personal to fix } \\
\text { containers in } \\
\text { transit }\end{array}$ & $\begin{array}{c}?- \\
\text { unspecified }\end{array}$ & $x$ \\
\hline $\begin{array}{c}\text { Part } \\
\text { Decisions }\end{array}$ & $x$ & $x$ & $x$ & $\begin{array}{c}\checkmark \text { - decides if } \\
\text { food inside is } \\
\text { perishing }\end{array}$ & $\begin{array}{l}\checkmark \text { - predicts } \\
\text { shelf-life }\end{array}$ & $x$ & $x$ & $x$ \\
\hline $\begin{array}{l}\text { State of } \\
\text { Research }\end{array}$ & Theoretical & $\begin{array}{l}\text { Prototype / } \\
\text { Field trials }\end{array}$ & $\begin{array}{l}\text { Prototype / } \\
\text { Field trials }\end{array}$ & Prototype & $\begin{array}{l}\text { Reduce-scaled } \\
\text { prototype }\end{array}$ & Commercial & Commercial & Commercial \\
\hline
\end{tabular}

*- this is no longer an active business

This review highlighted a gap in not only mobile containers that identify their contents and make decisions for both itself and the items it holds but also in physical deployment of these types of devices. The current focus for these types of devices also appears to be related to the monitoring of shipping containers within the food supply chain rather than inside a manufacturing domain.

Types of smart containers/holders which could uniquely identify their contents included (i) smart shelves, (ii) smart shipping containers with options to sense products and (iii) a forklift monitoring system that would identify the pallets it picked up using UHF RFID tags on the pallets (in this instance the forklift is behaving as the container). While other studies have been completed looking into smart shelving the paper selected went into detail about the operational reasons for having one and as these types of containers are static by design a larger review was not required. Smart selves can make operational decisions based upon how many items are held and demand for these [27], however these are decisions for the shelf and not the individual items. The two examples of constituent item decision making were 
found within academic research into the cold food supply chain where chemicals [30] and temperatures [30], [31] were monitored to determine the shelf life of food (i.e. how close to expiring).

The research presented in [31] was the only work in the comparison that presented a mobile container (i.e. shipping container) that was able to identify its components (i.e. RFID-tagged pallets) and make decisions for these components (i.e. shelf life prediction based on monitored temperatures inside the container) and decide whether it, as the container, was required to notify people. This piece of research ([31]) is part of a larger initiative undertaken by the University of Bremen into intelligent containers within the food supply chain [37].

There are very few identified real world examples of truly intelligent mobile containers, other than those discussed previously and many others which are similar in functionality, i.e. have embedded sensors, but typically used for data logging and have no active intelligence. Despite this, the subject is a very relevant research topic addressing the benefits of CPSs and manufacturing efficiency e.g. [38]-[41].

\section{Design of the Intelligent RTI}

The intelligent RTI can manage information, notifications and decisions on behalf of the components (possibly intelligent) within the manufacturing environment. Once components have been unloaded from an RTI, the RTI can be associated with the next set of incoming components and the previous components can interact with the next stage of production, i.e. the next assembly or manufacturing process.

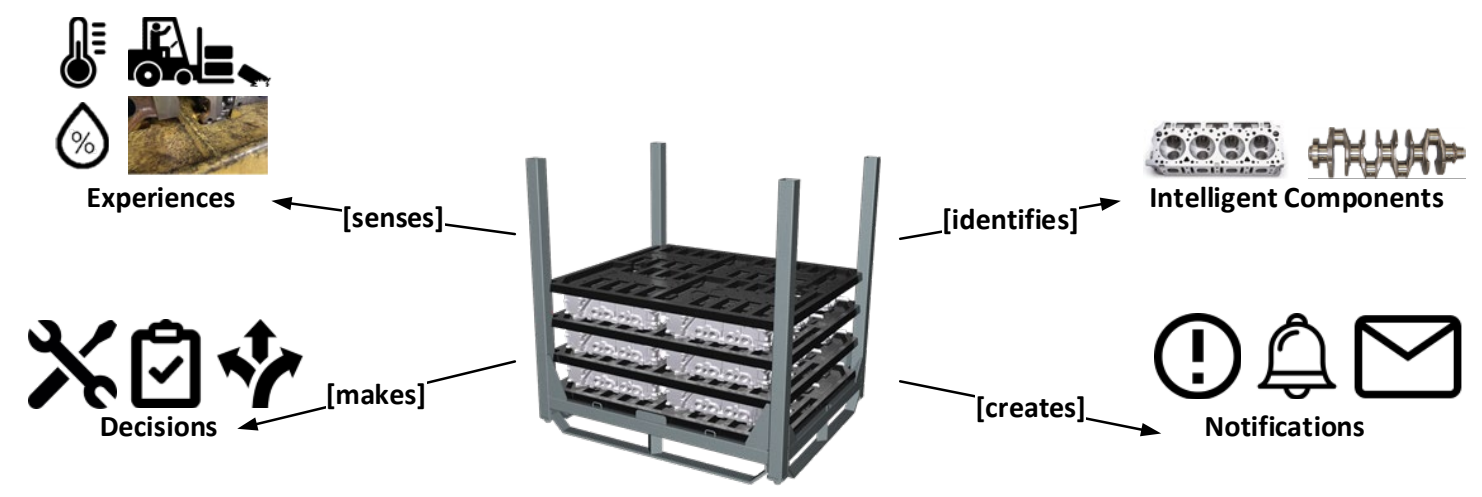

Figure 2 - An intelligent container overview

Figure 2, shows an overview of some of the functionality of an intelligent RTI. Specifically, the RTI needs: (i) to sense experiences, i.e. hot and cold experiences, occasions of poor transport handling (e.g. drops, shocks and their locations) and cleanliness, (ii) to identify and communicate with other intelligent products, (iii) to make decisions, i.e. to relocate the RTI, initiate a component or RTI inspection and to initiate RTI repairs and (iv) to be capable of publishing notifications i.e. to issue warnings, reminders or updates. Intelligent Container Architecture

To develop an intelligent container a CPS reference architecture has been proposed within this research that allows intelligent products to be integrated within manufacturing systems. The CPS challenges addressed within the architecture include: (i) Adaptability to cope with changes in RTI routes and business processes [42], [43], (ii) Scalability, any system should be scalable to meet an increase in demand by implementing effective communication protocols and system resource balancing [44], i.e. when more RTIs, more facilities and more users are introduced, (iii) Extendibility, to include the addition of new RTI types and future technological changes, i.e. integration of additional RTI sensors [45] and (iv) Security, any CPS should provide resource control and provide protection from unauthorised disclosure from techniques such as "man-in-the-middle", denial of service and injection of fake data from third parties [44]. The proposed reference architecture, Figure 3, to meet these requirements is a combination of both a Service Orientated Architecture (SOA) and the Reference Architecture Model for industry 4.0 (RAMI4.0) [46]. The SOA is a paradigm for the reuse, interoperability and development of services [47]. The RAMI4.0 reference architecture has been developed from a collaboration between the technical committees of the VDI/VDE Society of Measurement and Automatic Control (Specifically, Industry 4.0 and Cyber-Physical System committees) [46]. The RAMI4.0 architecture focuses on high levels of interaction within layers (representing different manageable parts, i.e. the asset layer, integration layer and 
functional component layer) and loosely coupled connections to the immediate layer above and below [46]. As with a SOA, at higher layers of the hierarchy, there is a shift from a unique device perspective to a business process and service abstraction perspective. It was determined that the SOA best describes the interaction between components, however, it does not consider the asset layer (i.e. Intelligent RTIs and components) and how they can integrate within a CPS. To solve this, the proposed reference architecture includes an Asset layer and an Integration layer like that represented in the RAMI4.0 within a SOA reference architecture [48]-[52]. The Integration layer provisions a Service Bus that provides protocol translation, service discovery, service routing, security and network integration. The addition of a service bus solves some of the issues related with a SOA and CPSs, such as excessive point-to-point communications [50], [53], i.e. many service endpoints residing at uniform resource locators (URLs) [54], and supports integration of differing technologies, i.e. can integrate Wi-Fi, ZigBee, WSNs and other networking platforms into a CPS. In summary, there are 6 representative layers within the architecture: (i) the asset layer represents the unique realworld assets, in this case intelligent products (i.e. intelligent RTIs and intelligent components), (ii) the integration layer, representing the service bus and how differing technologies can integrate the real world into the CPS, (iii) the service implementation layer, describing the individual service implementations that provide well defined services, i.e. data capture, data filtering and data analytics, (iv) the service abstraction layer describes fundamental business service, i.e. scheduling, RTI locating and monitoring, that orchestrates service implementations from the layer below, (v) The business process layer orchestrates a number of service abstractions to define a particular business function, i.e. dynamic RTI control or quality control monitoring and finally, (vi) the application layer describes the interaction of business processes to define an application, i.e. intelligent manufacturing.

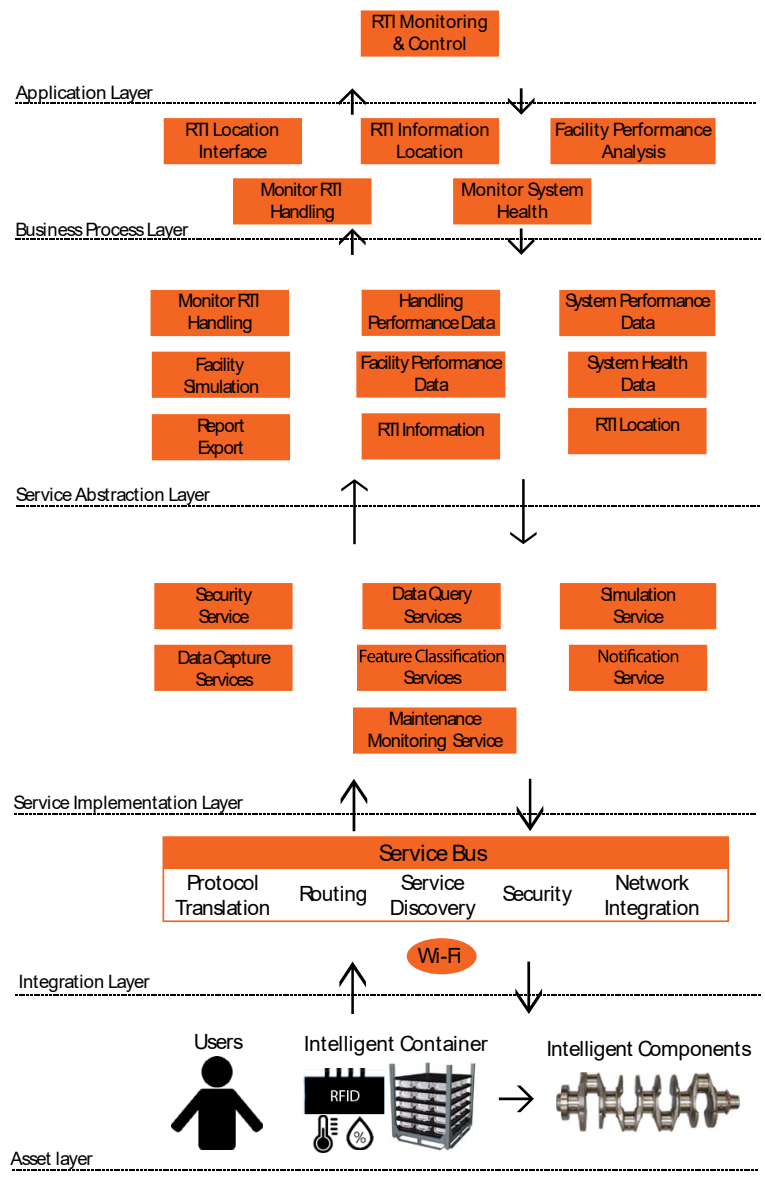

Figure 3 - Reference architecture with an intelligent container and intelligent components

Integration between the RTI and the CPS, occurs through wireless connectivity (i.e. ZigBee, Bluetooth or Wi-Fi) rather than traditional RFID interrogation with intelligent components continuing to integrate with the CPS either through an integration layer based RFID interrogator or the intelligent container. 
Many services, such as feature determination, data capture and handling performance data can be offloaded from the CPS and embedded within the intelligent container, reducing the computational needs of a CPS software implementation. Previous research has investigated the performance of a low intelligence RTI [55], i.e. comprising a passive UHF RFID tag, that could not process data and as such, analysis must be undertaken within the CPS software implementation. The intelligent container concept increases the adaptability and extendibility of the architecture as when new intelligent containers and components are introduced, the required services for them to operate are embedded on the asset layer, meaning the CPS is not strictly required to implement new services. This also has the beneficial side effect of making the architecture more decentralised, with intelligent containers implementing processing capability, offloading it from the central CPS implementation. The CPS can offer services with relevant rules developed on the business process layer to adapt functionality with the introduction of new intelligent assets if required. As an example, with respect to the identification of poor handling, feature recognition techniques or impact thresholds may differ between the handling of an intelligent RTI and an intelligent product, i.e. a headlight assembly vs. a stainless steel RTI, with one able to experience larger collision or drop forces before being damaged. With the intelligence embedded at the asset layer, the CPS can be agnostic to these differences, but can still react to damage, i.e. instruct an asset inspection, move an asset to a quarantine area or to notify stakeholders. With this in mind, traditional RFID portal architecture implementations tend to be based upon an account-based data model [21], in which movement of RTIs is represented as a set of transactions that update the RTI and component quantities in each respective location throughout the factory. In contrast, the implementation of an intelligent RTI and intelligent products requires a product centric approach, which provides additional flexibility / adaptability for all intelligent container and intelligent product types and instances [21]. Thus, each intelligent product and intelligent container needs to be uniquely addressable with its own information model and associated embedded services.

To achieve this, it is proposed that rather than using an account based data model, where updates to state changes are reflected in a database, intelligent components have a permanent communication link on which the CPS can query intelligent products' data models, listen for notifications (i.e. location updates, poor handling events or the detection of intelligent components) and actively initiate commands (i.e. move to repair, request an inspection or hold until further notice). Therefore, the intelligent container architecture implements a "publish and subscribe" based service bus (Section 3.2.1) on the integration layer of the reference architecture to support the above requirements. The "publish and subscribe" architecture decouples the production and consumption of data within a system, allowing the production of notifications and subscription to events based upon data characteristics rather than by data source [56] i.e. a service can subscribe to temperature events from many data sources, without explicitly needing to connect to all devices publishing temperature related data. An example usage of the "publish and subscribe" service bus is shown as a Universal Modelling Language (UML) activity diagram in Figure 4.

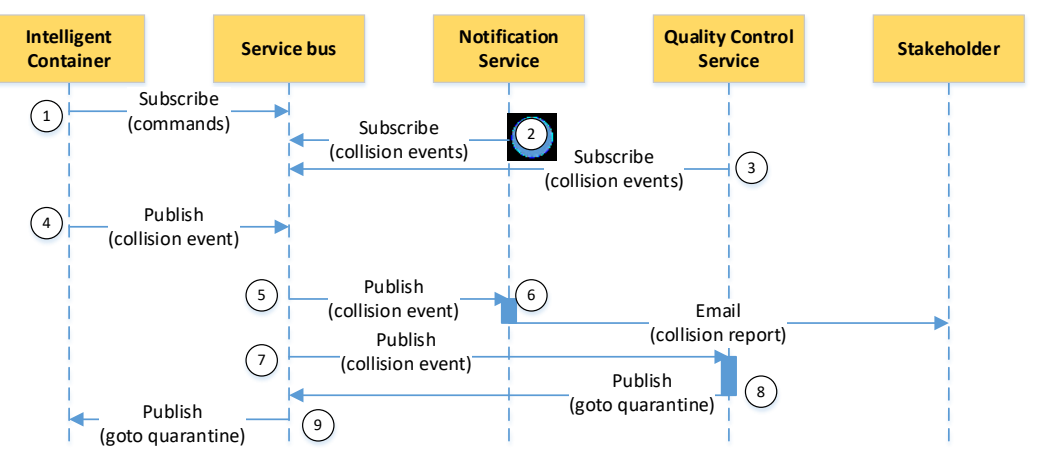

Figure 4 - Example usage of the publish and subscribe service bus

When an intelligent container comes online, each entity, i.e. the intelligent container or CPS services, subscribes to one or many topics, denoted 1, 2 and 3 in Figure 4. A topic is a name or reference for the type of information that an entity wishes to receive or publish data about. In this example, the reporting of an intelligent RTI collision (1 and 2) and for the sending of events (3). In the event that an RTI identifies a collision, it is responsible for publishing those data to the service bus on the collision topic, denoted 4. Once the published data have been received on the service bus, it simultaneously re-publishes the same information to all entities subscribed to that topic, in this case, the notification service (5) and the quality control service (7). At this point, both services undertake their role within the CPS, with the 
notification service compiling an email of the event to stakeholders (6) and the quality control service determining that the RTI requires to be quarantined, due to potential damage to components in the collision. This quarantine command is then re-published onto the service bus (8) and then onto to the intelligent container, which had previously subscribed to its respective command topic (9).

\subsection{Supporting Technologies}

This section describes the software technologies implemented to develop the proof of concept cyber-physical infrastructure for the intelligent container.

\subsubsection{Message Queue Telemetry Transport}

For the implementation of a "publish and subscribe" service bus the Organization for the Advancement of Structured Information Standards (OASIS) Message Queuing Telemetry Transport (MQTT V3.1.1) technology is utilised [57]. The MQTT standard defines a one to many publish and subscribe messaging service that is payload agnostic. The standard also implements quality of service distribution techniques for traffic management, "at most once" - a single message delivery attempt is made but not guaranteed to succeed based on traffic and network conditions, "at least once" - a message is guaranteed to arrive, but duplicates may occur and "exactly once" - a payload is guaranteed to be delivered exactly once. There are a number of published usages of the MQTT standard within cyber physical systems as presented in [58]-[60]. Additionally, the MQTT protocol has been shown to be suitable for wireless devices, as required by the smaRTI hardware, as it has a lower power requirement than that of an equivalent open HTTP connection $(27.9 \%$ reduction in power for sending data)[61], [62]. To implement the MQTT standard an MQTT broker is required. An MQTT broker is the software implementation of the MQTT standard with respect to server-side operations, i.e. allows and maintains TCP/IP connections with devices, applies security protocols and is responsible for the republishing of messages and handling subscriptions. For this research the Mosquitto MQTT broker was implemented [63].

\subsubsection{Node-Red}

To develop supporting intelligent container services, a software package "Node-Red" was integrated [64]. Node-Red is a flow based programming tool designed for developing applications within the internet of things domain [64]. Node-Red provides a web browser based development environment with Node.JS [65] and JavaScript foundations. The platform is a flow based programming environment, built around modern internet technologies such as MQTT, Hyper Text Transport Protocol (HTTP), Websockets, JavaScript Object Notation (JSON) and eXtensible Markup Language (XML). A software developer can drag and drop nodes representing software functionality and place interconnects representing the flow of data. Within Node-Red, programming is not limited to existing nodes and flow based design, JavaScript function blocks can also be developed. The advantages of utilising Node-Red for this research is that it supports technologies such as MQTT and provides tools for rapid development, prototyping and integration of software functionality. Thus, for the development of an intelligent container, effort can be focused on software services, rather than developing and implementing a bespoke integrated software stack as provided by Node-Red, whilst adhering to the reference architecture proposed in this research.

\section{4 smaRTI Hardware and Software Development}

\section{1 smaRTI Hardware Implementation}

For the successful implementation of product monitoring, which refers to the physical handling and environmental conditions that components experience when in an intelligent container, there is a need to monitor environmental parameters, i.e. via accelerometer, gyroscope, magnetometer (compass), temperature, humidity and altimeter (pressure) sensors. Through processing and understanding of sensor features the intelligent RTI is capable of monitoring product experiences, such as impacts (i.e. collisions / drops) and temperature or humidity exposure. Beyond the collection of environmental data and locating intelligent components there are four other fundamental requirements that are necessary to achieve RTI intelligence: (i) data processing, the hardware must have embedded processing capability that is able to sample connected sensors, perform data manipulation (i.e. filtering, feature extraction and pattern recognition [66], [67]) and to compute the resultant information via rules representing decision making criteria, i.e. classifying what represents an RTI collisions or drop, (ii) data storage for sensor data, RFID interrogator data and the intelligent container's information model. This storage additionally acts as a buffer between 
the local device (RTI) and the cyber-physical monitoring system providing a level of resilience to communication errors or lack of a communication channel (i.e. no wireless signal), (iii) wireless communication, to provide real-time data dissemination, controls and RTI notifications, the intelligent RTI requires a wireless communication link [68]. The wireless link also represents the bridge between the asset layer and integration layer of the reference architecture and (iv) a power source is required to support all of the data collection, processing, storing and communication activities[69], such as battery cells [70] or fuel cells [71]. These requirements have driven the smaRTI hardware design leading to the component selection outlined in Table 2.

Table 2 - The smaRTI Hardware Components

\begin{tabular}{|c|c|}
\hline Hardware & Description \\
\hline $\begin{array}{l}\text { Wi-Fi and Microcontroller } \\
\text { module (Espressif ESP-12E) }\end{array}$ & $\begin{array}{l}\text { The ESP8266 is a low cost }(£ 1.46) \text { and low power }(1.2 \mathrm{~mW}) 32 \mathrm{bit} \\
\text { microcontroller with full TCP/IP stack and Wi-Fi communications (IEEE } \\
802.11) \text {, also includes up to } 16 \mathrm{MiB} \text { of flash storage. }\end{array}$ \\
\hline $\begin{array}{l}\text { UHF RFID module (ThingMagic } \\
\text { Nano) }\end{array}$ & $\begin{array}{l}\text { The ThingMagic Nano is a fully capable UHF RFID interrogator module } \\
\text { designed for embedded systems with an API for application development. }\end{array}$ \\
\hline $\begin{array}{l}\text { 3-Axis digital compass } \\
\text { (Honeywell HMC5883L) }\end{array}$ & $\begin{array}{l}\text { The HMC5883L is a surface mount } 3 \text {-Axis digital compass IC capable of a } 1^{\circ} \\
\text { to } 2^{\circ} \text { compass heading accuracy. }\end{array}$ \\
\hline $\begin{array}{l}\text { 3-Axis accelerometer (Analog } \\
\text { Devices ADXL345) }\end{array}$ & $\begin{array}{l}\text { The ADXL345 is a surface mount 3-Axis accelerometer capable of measuring } \\
\text { at up to } \pm 16 \mathrm{~g} \text {. }\end{array}$ \\
\hline $\begin{array}{l}\text { 3-Axis gyroscope (InvenSense } \\
\text { ITG-3200) }\end{array}$ & $\begin{array}{l}\text { The ITG-3200 is a surface mount 3-Axis gyroscope capable of measuring of } \\
\text { up to } \pm 2000 \% \text { s. }\end{array}$ \\
\hline $\begin{array}{l}\text { Humidity and temperature } \\
\text { sensor (Sensirion SHT21) }\end{array}$ & $\begin{array}{l}\text { The SHT2 } 1 \text { is a fully calibrated surface mount temperature and humidity } \\
\text { sensor capable of measuring } 0-100 \% \text { relative humidity }( \pm 2 \% \mathrm{RH}) \text { and }-40 \\
\text { to }+125^{\circ} \mathrm{C}\left( \pm 0.3^{\circ} \mathrm{C}\right)\end{array}$ \\
\hline $\begin{array}{l}\text { Absolute pressure sensor (NXP } \\
\text { MPL3115A2) }\end{array}$ & $\begin{array}{l}\text { The MPL3115A2 is a surface mount barometric pressure sensor capable of } \\
\text { measuring up to } 50-110 \mathrm{kPa}(10 \mathrm{~km} \text { Altitude) with a } 0.3 \mathrm{~m} \text { altitude } \\
\text { resolution. }\end{array}$ \\
\hline Piezoelectric buzzer & $\begin{array}{l}\text { A piezoelectric buzzer for generating tones for audio based alerts and } \\
\text { notifications. }\end{array}$ \\
\hline $\begin{array}{l}128 \times 64 \text { I2C OLED graphical } \\
\text { display }\end{array}$ & An OLED display for visualising on-board debug and error messages. \\
\hline
\end{tabular}

Figure 5 shows a fully manufactured and assembled smaRTI board with all the environmental sensors, Wi-Fi module, 0.96 " OLED display and RFID interrogator attached.

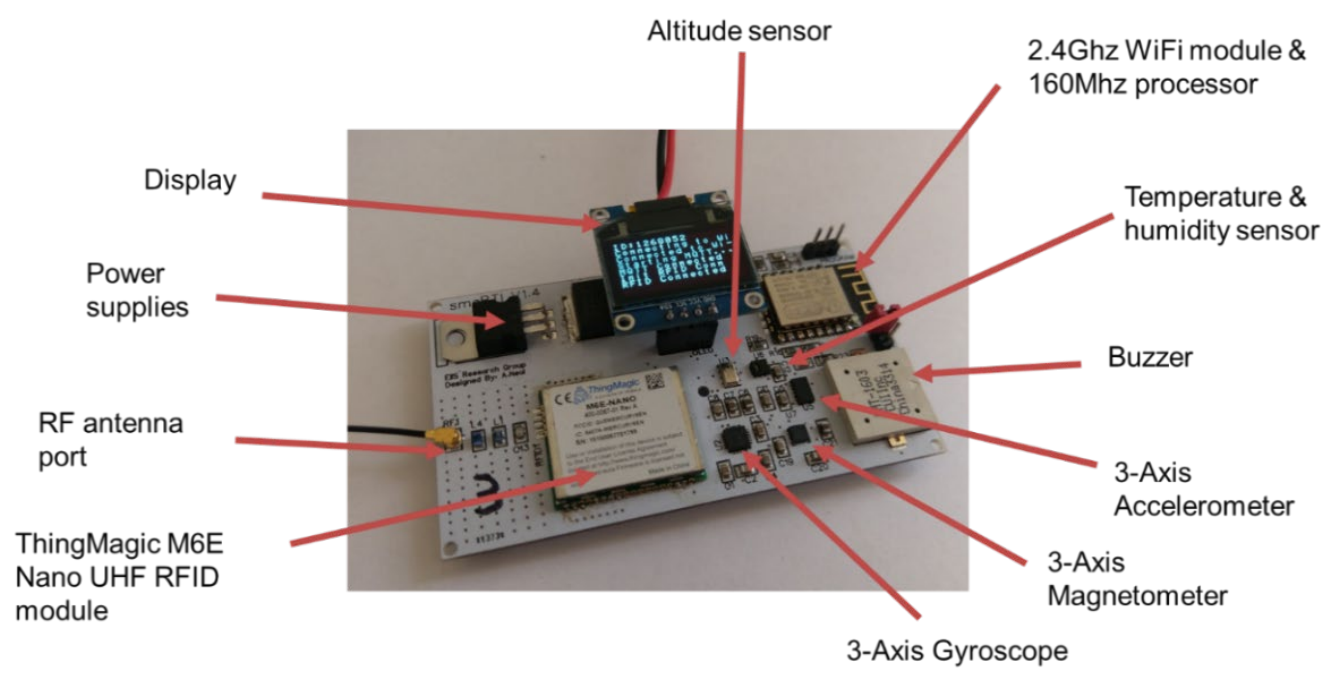

Figure 5 - Unpackaged smaRTI hardware 


\section{2 smaRTI Software Implementation}

Figure 6 presents a UML component diagram describing how the CPS reference architecture maps to the implemented technologies and software requirements for the implementation of an intelligent container embodied within the smaRTI hardware. There are 4 fundamental components: (i) Node-red (NR.1), (ii) the MQTT Communications (MC.1), (iii) the Intelligent Container application software (IC.1) and (iv) instances of intelligent products (IP.1). IC.1 and IP.1 represent assets located on the asset layer of the reference architecture, with IC.1 containing a number of software services, such as the logging service (IC.1.6) and sensor capture services (IC1.4). MC.1 represents the service bus on the integration layer and finally, NR.1 represents the service implementation, service abstraction and business process layers of the architecture.

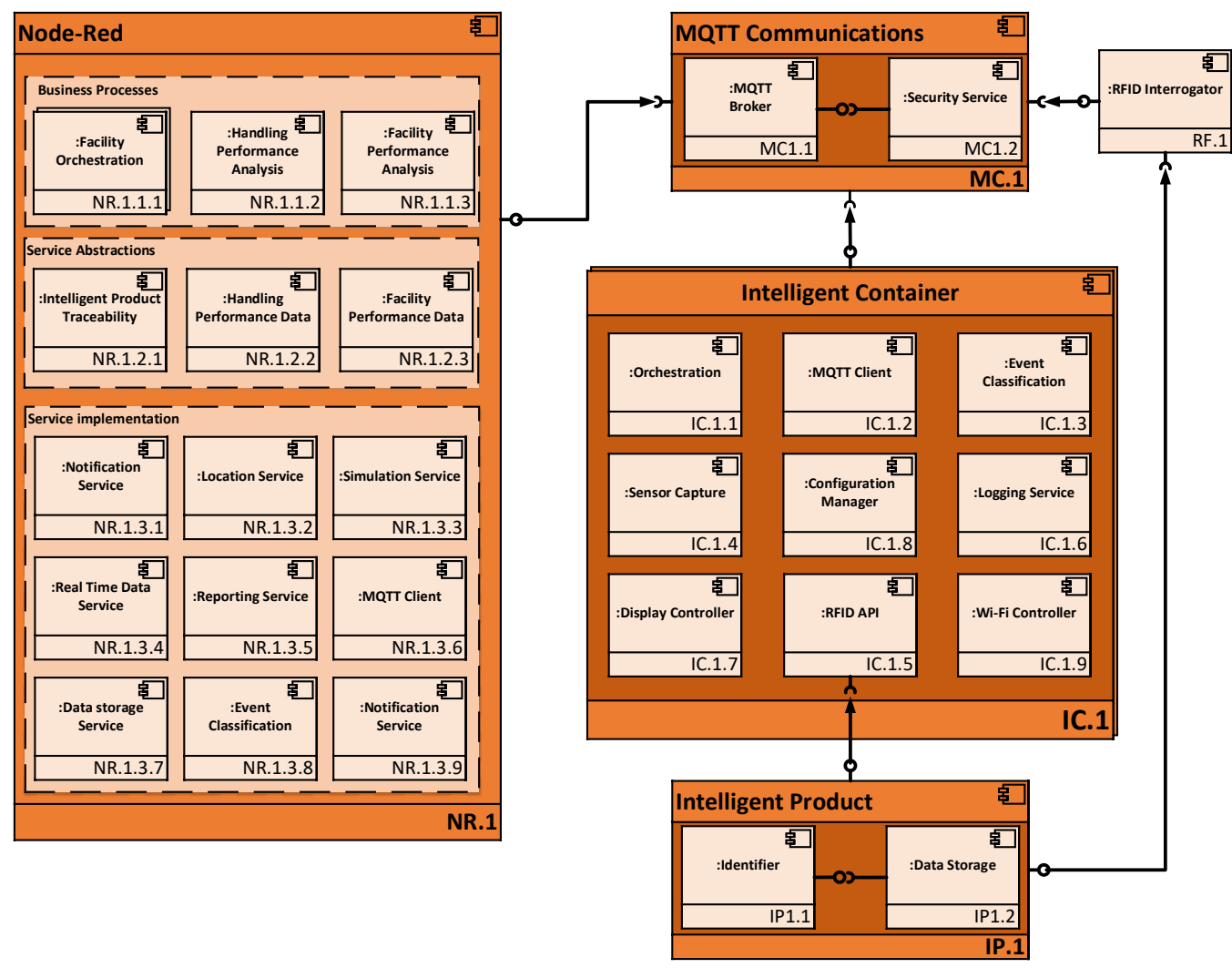

Figure 6 - UML Component diagram for the smaRTI software architecture implementation

Each instantiation of the intelligent container (IC.1) is capable of interacting with the service implementations through the MQTT component (MC.1), with each intelligent product instantiation (IP.1) interacting through the intelligent container (IC.1) or through the RFID interrogator (RF1) and then MC.1, the latter form of interaction being similar to that of the traditional RFID portal based architectures

\subsection{Graphical User Interface}

To monitor and capture data from the smaRTI hardware during use, accompanying Graphical User Interfaces (GUIs) have been developed. The GUIs reside within the Node-Red environment and display real-time data being experienced by the intelligent container. Figure 7 represents an interface for the representation of inertial measurement information that is displayed in 3 charts representing the accelerometer, gyroscope and magnetometer data. On the right-hand side, the current altitude, temperature and humidity data are presented below a list of currently available RFID tags detected within the intelligent container (i.e. representative of intelligent components such as crankshafts). 


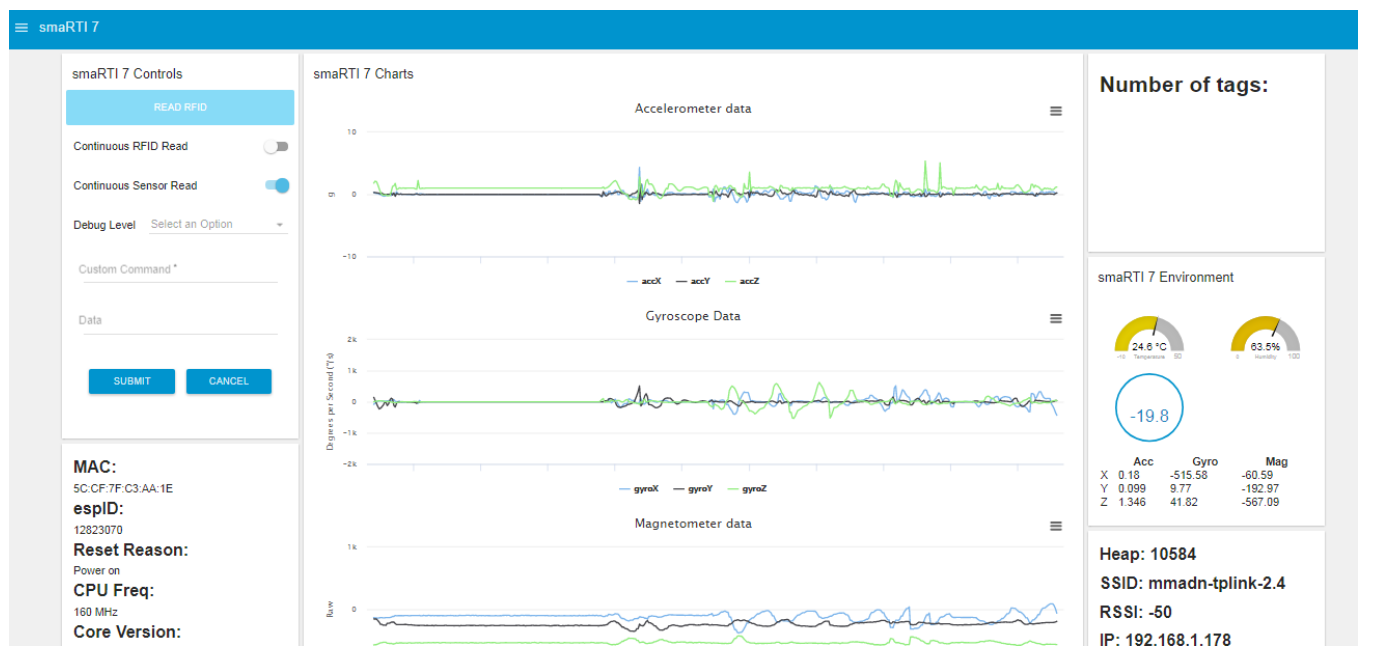

Figure 7 - sMaRTI IMU Visualisation

Due to the adaptability requirement of the CPS it is required that monitoring thresholds can be set for each intelligent device. Therefore, for unique intelligent containers or products, it is possible to define the data thresholds for what should be considered an "event". An "event" refers to when something of importance occurs, i.e. an RTI has been dropped or an intelligent product has experienced out of specification values of temperatures or humidity. The smaRTI hardware has been equipped with sensors (e.g. accelerometers, gyroscope and magnetometers) for the identification of such events i.e. drops, collisions and tilting. With this in mind, the per device thresholds have been determined to be the collision force (force of the impact in horizontal plane), drop force (i.e. force of impact in vertical plane), tilt angle (i.e. angular deviation of vertical plane), a temperature excursion (defined as high and low temperature limits, i.e. $5^{\circ} \mathrm{C}<$ $t<50^{\circ} \mathrm{C}$ ) and the duration for which the temperature has been exceeded and humidity excursion (i.e. $h>80 \% \mathrm{RH}$ ).

Figure 8 , shows the user interface that has been developed to allow stakeholders to adjust the monitoring thresholds and the global notification settings, i.e. the email address that receives notifications.

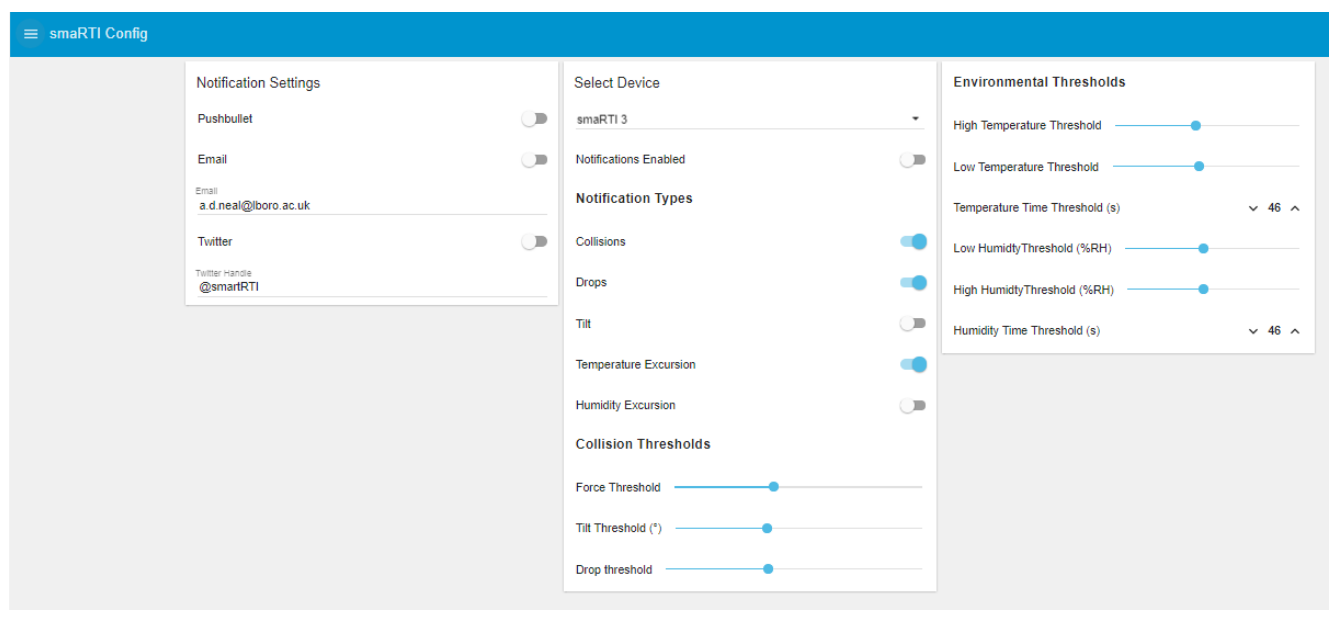

Figure 8 - Configuration of intelligent container monitoring thresholds for event classification

\section{RTI Intelligence}

A series of contextual information can be determined to identify the state of an RTI and its constituent items i.e. to determine when an RTI is full, empty, requires attention (e.g. damaged or dirty), has experienced poor RTI handling, poor environmental conditions and for the identification of loaded components. Such derived information can then be used to make decisions by the RTI.

As specified in Section 3 the RTI needs: (i) to sense experiences, (ii) to identify and communicate with other intelligent products, (iii) to make decisions and (iv) to be capable of publishing notifications. The publishing of notifications has 
been covered within the design (Section 3.1). This section will discuss the feasibility for determining the RTI experiences, identification of contained products and the potential decisions which could be made. For these studies an automotive manufacturer RTI has been utilised. The RTI is of a steel construction and holds up to 18 cylinder heads for a 4-cylinder diesel engine. These RTIs are part of a closed-loop supply chain with up to 1000 RTIs in circulation at any one time.

\subsection{RTI and Component Experience}

This section discusses how the use of inertial measurement devices embedded within an intelligent RTI could be leveraged to gain an understanding into the handling performance of an RTI. Specifically, by monitoring the accelerometer, gyroscope and magnetometer outputs it may possible to identify kinematic features that represent RTI activities such as raising and lowering an RTI from a forklift and identification of transport features, i.e. turning and detecting the occurrence of collisions.

\subsubsection{RTI Collisions}

An RTI can be exposed to harsh collisions when being moved with a forklift truck. To identify when a component and an RTI may require attention, due to a collision or drop, would provide benefits to stakeholders by highlighting an early indication that components might be damaged, or an RTI may require repair. To determine this information before the $\mathrm{RTI}$ is in the critical path of manufacturing processes, will help to ensure possible production line stoppages are avoided. Similarly, data representing the frequency and location of such incidents within a facility, could be used as a tool for process improvement, identifying incident hotspots which could be addressed. Figure 9 presents data ( $\mathrm{Y}$-axis, horizontal in line with travel direction) from two RTIs colliding. During the collision the sensors were sampled at $50 \mathrm{~Hz}$. The movement starts with a normal forward acceleration of the forklift, denoted 1. After a period of 9 seconds the RTI collides with another, which is filled with components and resting on the ground, denoted 2 . The forklift is then slowly reversed away from the static RTI, with some slight scraping between RTIs, denoted 3. Finally, the RTI continues reversing away from the collision location and comes to a rest, denoted 4.

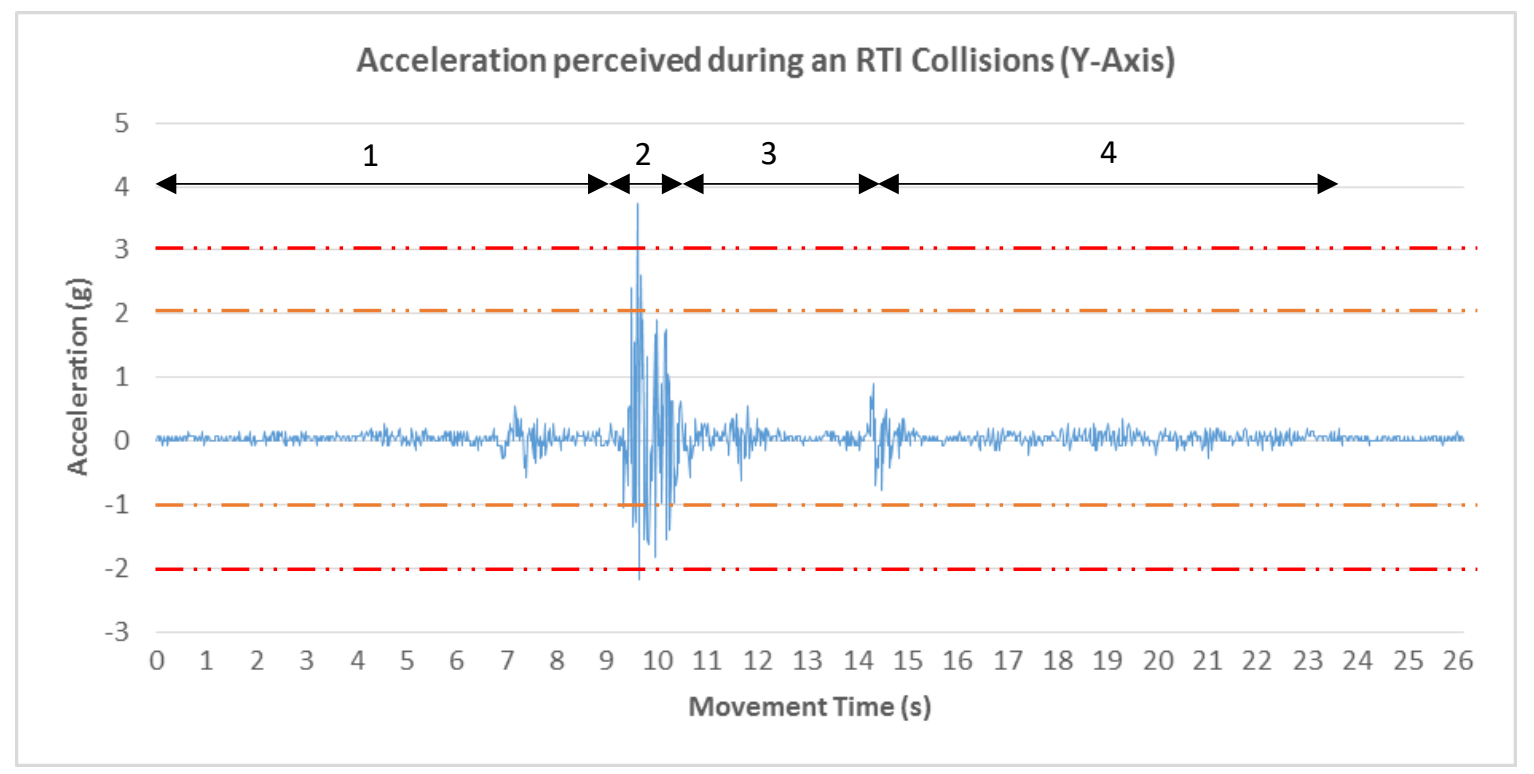

Figure 9 - Acceleration perceived during an RTI collision

The feature of interest is the collision between the two RTIs at position 2. During the collision, high levels of peak acceleration ( $3.74 \mathrm{~g}$ to $-2.19 \mathrm{~g}$ ) were observed. For the detection of collisions, it is therefore proposed that a thresholding process can be used to identify the occurrence of RTI collisions. For example, a lower threshold limit of $+/-$ $1 \mathrm{~g}$ could be set to indicate less severe incidents where component damage is less probable, with a threshold of $+/-2 \mathrm{~g}$ to represent critical incidents where component damage is probable. These threshold limits are shown on Figure 9 as an orange dashed bar (less severe incident) and a red dashed bar (critical incident). In this scenario the collisions would be considered critical in nature as the peak acceleration $(3.74 \mathrm{~g})$ is greater than the $2 \mathrm{~g}$ threshold limit. This research has 
not yet investigated the relationship between the severity of an RTI collision and the resultant component or RTI damage, but rather the potential for an intelligent RTI to detect collisions utilising on-board sensors.

\subsubsection{RTI Lifting}

One feature of RTI handling that can be monitored is the lifting and lowering of an RTI. This feature could be useful for identifying when a forklift has collected an RTI and in the process of being moved, i.e. when lifted, the RTIs location is likely to change. Conversely, when an RTI is lowered it is likely to indicate that an RTIs location is likely to remain the same. It is proposed that the altimeter can determine the current altitude of the RTI, for the purposes of identifying when an RTI is lifted, or the height at which it is located when left in storage areas. To assess the viability of this, an RTI was mounted to a forklift and had its height increased by $30 \mathrm{~cm}$ every 10 seconds to the maximum working height of the forklift $(4.3 \mathrm{~m})$. Figure 10 presents the output of the altimeter which was calibrated to $0 \mathrm{~m}$, when stationary on the ground. A 10s moving average filter was applied to the raw data to attenuate the noise present within the raw data. The data show that the general trend of the measured altitude (gradient of 10 s average $=0.03261$ ) and the actual movement (gradient $=0.02958$ ) are similar, although there is evidence of an offset $(0.00303$, a $9.29 \%$ difference) possibly resulting from a need to calibrate the sensor on the day of operation. Nevertheless, it is evident that there is a significant amount of noise in the raw data, i.e. the std. deviation at $0.6 \mathrm{~m}$ and $0.9 \mathrm{~m}$ was $0.48 \mathrm{~m}$ and $0.47 \mathrm{~m}$ respectively. This uncertainty means that small changes in forklift height, i.e. those producing enough ground clearance for the forklift to move (10 to $30 \mathrm{~cm}$ ), may not be identified robustly from the altimeter alone. Note: The MPL3115A2 sensor has a pressure reading noise of 19 to $1.5 \mathrm{~Pa}$ RMS (1.58 $\mathrm{m}$ to $0.12 \mathrm{~m}$ ) depending on the level of sensor oversampling (i.e. $128 \mathrm{x}$ to $1 \mathrm{x})$ and acquisition rate $(100 \mathrm{~Hz}$ to $1 \mathrm{~Hz})$ [72]. However, movements that stack an RTI on top of another can be identified as the change in height is significantly greater than the altimeter resolution (e.g. $+1 \mathrm{~m}$, or the height of the RTI type). Rapid changes in altitude, i.e. $\pm 1 \mathrm{~m}$ within 10 s, could be missed due to the level of sensor noise and the level of filtering required. However, for long-term altitude monitoring (i.e. determining location of individual RTI's within a stack) the filtered data are capable of identifying changes in absolute RTI heights. Due to changes in weather conditions the absolute pressure at sea level will vary [73] meaning the altimeter requires regular calibration to account for this. It is proposed that the sensor can be zeroed periodically (i.e. every 15 minutes) during periods of inactivity, making the recorded altitude relative to current RTI position rather than sea level. In this case an intelligent RTI could identify when it is raised (positive change in altitude), or lowered (negative change in altitude). Once an RTI has been lowered, or becomes inactive, the calibration process can repeat. This would allow an intelligent RTI to identify lifting and lowering processes during RTI operations.

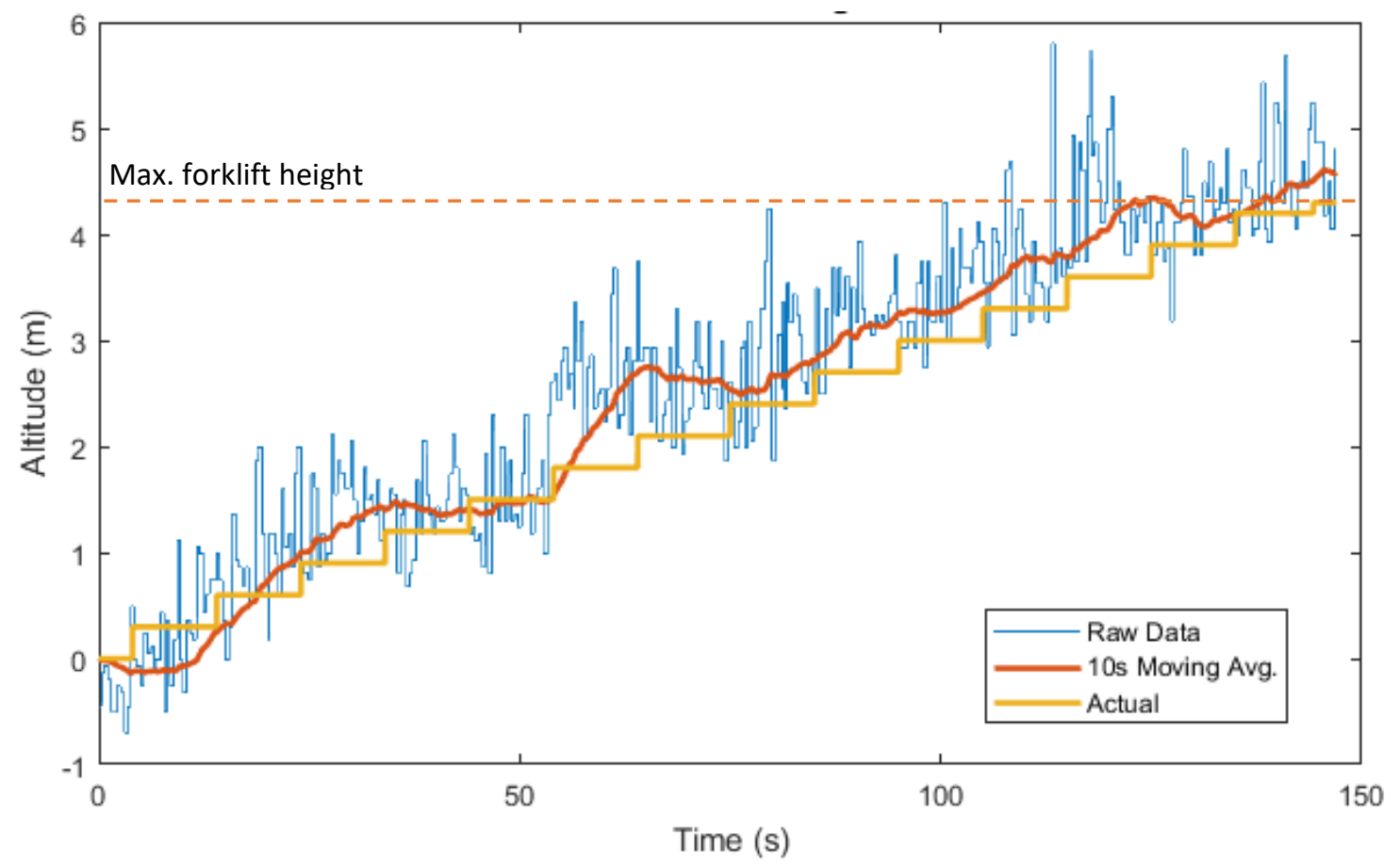

Figure 10 - Comparison of the measured, 10s moving average and actual altitude of an RTI being lifted 


\subsubsection{RTI Turning during transport}

There are many techniques employed to determine the location of an asset utilising wireless technologies, such as Time Difference On Arrival (TDOA) [74], Angle of Arrival (AOA)[75] and received signal strength indicators (RSSI)[76], with integration of the techniques utilised to improve the accuracy of location [77]. With the addition of inertial measurement devices, it is proposed that the additional gyroscopic and magnetometer sensors can be used to detect other logistical events, i.e. turns, which could indicate the location or deviation from planned routes of an RTI. Examples of leveraging the use of gyroscopic data in location and path determination can be found in [78] and [79]. Many manufacturing facilities have orthogonal layouts, where many turns are $90^{\circ}$ rotations. Thus, an RTI is constrained to strict routes when being moved with a forklift, limiting the number of physical locations and routes. By identifying the occurrence and direction of turns as well as time periods between them, it could be possible to derive the route that the forklift is taking, further improved when fused with the other location algorithms previously mentioned. Figure 11 presents the gyroscopic data (vertical z-axis) of an RTI being transported through three $90^{\circ}$ turns. The route is a left turn, followed by a right turn and a final left turn. To identify the occurrences of these events the following data processing techniques have been used: (i) a simple moving average filter to smooth the raw gyroscope data (i.e. angular velocity), (ii) integration of the angular velocity to determine angular displacement, (iii) thresholding of angular displacement within a small time frame (i.e. time for a turn, approximately 1 to 3 seconds) to determine the occurrence of significant changes in angular displacement, identifying a turn, (iv) peak detection is then used to determine the maximum displacement, representing the amplitude of the turn. For the data presented in Figure 11 a time span of 3 seconds and a $0.6 \mathrm{rad}\left(34.4^{\circ}\right)$ threshold value were used. These thresholds enable the 3 turns to be readily identified, the first a $-1.46 \mathrm{rad}\left(-83.7^{\circ}\right)$ left hand turn, the second a $+1.64 \mathrm{rad}\left(94^{\circ}\right)$ right hand turn and finally a $+1.57 \mathrm{rad}\left(90^{\circ}\right)$ left hand turn, matching actual movements undertaken by the RTI and forklift.

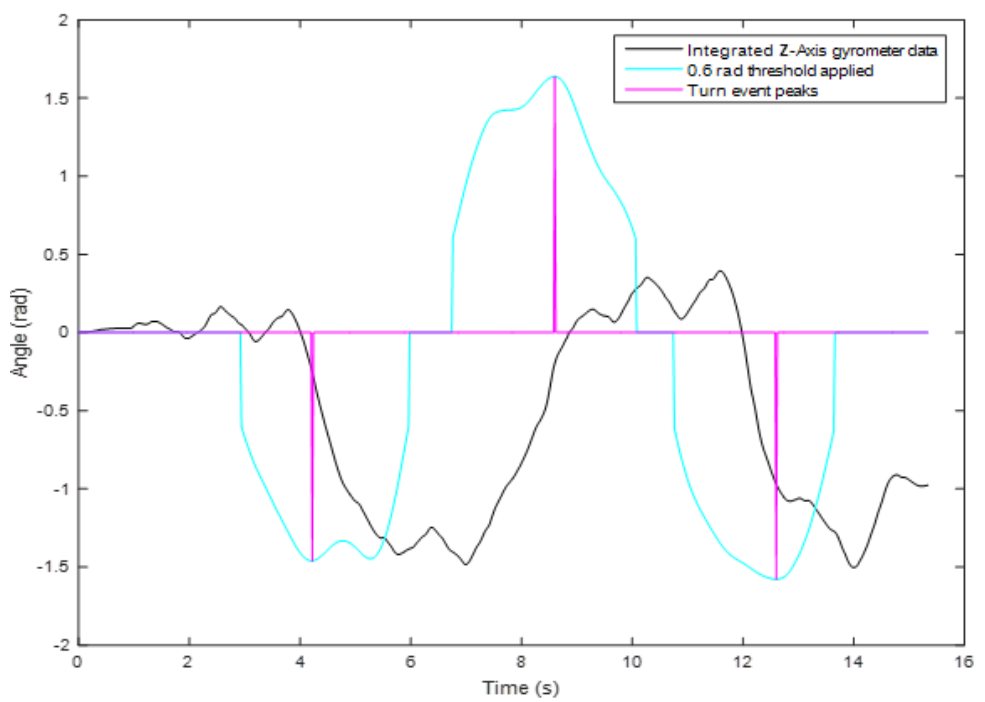

Figure 11 - Peak detection algorithm identifying angular displacement of detected turn events

\subsection{Identification of components}

The ability to determine whether an intelligent container is full or empty of components aids stakeholders and a cyberphysical RTI monitoring system to determine the next expected processes based on a set of decision making criteria, i.e. does the RTI need moving to the assembly line, or to a holding area? Further to this, having the ability to identify components that have been placed onto the RTI, will aid quality and productivity processes via higher levels of traceability and allow CPSs make better informed decisions with a higher level of granularity (i.e. at the individual component level). The collection of unique component identities could also benefit other business situations such as with component recalls and quality audits, where individual components can be traced through the supply chain by their association with a uniquely identifiable intelligent RTI. To enable this level of intelligence, it is imperative that an 
RTI can communicate with its constituent parts, i.e. detect the presence of components and query its data storage. To achieve this, it is proposed to embed UHF RFID tags into or affix onto automotive components. Due to the read range performance of the Xerafy Nano X II RFID tag (i.e. $4.4 \mathrm{~m})$ and small footprint $\left(31.7 \times 12.8 \mathrm{~mm}^{2}\right)$ this UHF RFID component was evaluated for its performance capabilities when applied onto a cylinder head. Three RFID tag positions were identified and investigated as shown in Figure $12(\mathrm{CH} 1-\mathrm{CH} 3)$. The positions were selected based on the need: (i) to have an area flat enough to fit the selected RFID tag. There are many manufacturing and geometric features, such as dimples and structural supports that limit potential locations and (ii) not to interfere with potential mating features, i.e. bolt holes and inlet or exhaust headers.

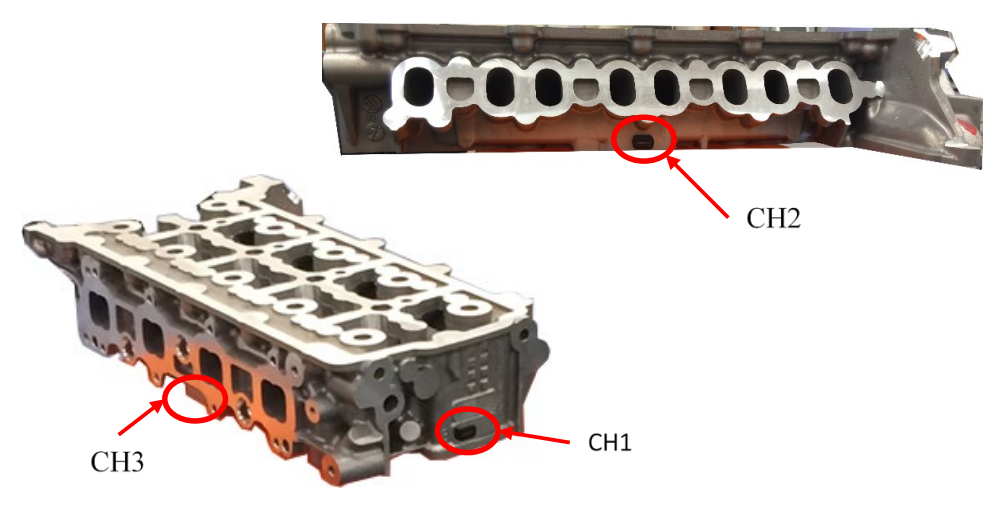

Figure 12 - Cylinder head RFID tagging locations

Figure 13 presents the RFID performance of the Xerafy Nano X II when placed into position CH1 of the cylinder head and measured at 4 angles of rotation with respect to the RFID interrogator antenna ( $0^{\circ}$ represents the antenna parallel with the RFID tag). At $0^{\circ}$ of rotation the Nano X II achieves a read range of $3.8 \mathrm{~m}(40 \% \mathrm{RSR}, \sigma=318)$, with the worst performing orientation at $90^{\circ}$ of rotation, where the Nano X II only achieves a $1.8 \mathrm{~m}$ read range $(80 \% \mathrm{RSR}, \sigma=305)$.

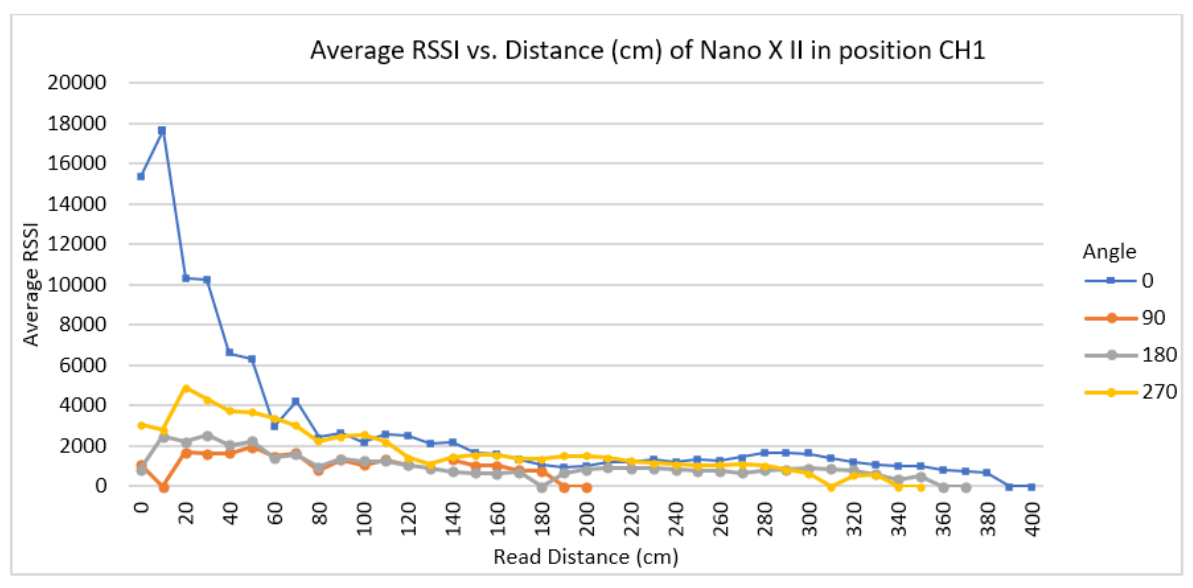

Figure 13 - UHF RFID read range of a Xerafy Nano X II on a cylinder head in position CH1

With the identification of a robust RFID tagging location for a cylinder head and corresponding RFID tag, a design of experiments was carried out to determine if individual cylinder heads could be read when placed within an RTI utilising an embedded UHF circularly polarised antenna. Figure 14 outlines the orientation of cylinder head within the intelligent RTI, with the red block identifying the RFID tag location. The RTI has 3 layers of components with a plastic separator between each layer. 


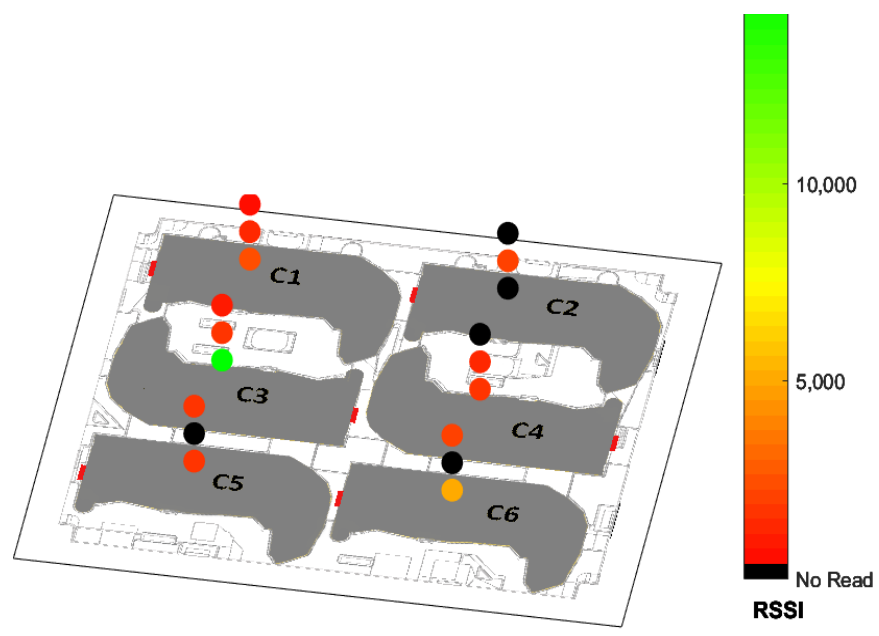

Figure 14 - Uniquely identifying cylinder head in a full RTI with a Nano X II (+27dBm)

The results show that at an output power of $+27 \mathrm{dBm}$ (maximum for the ThingMagic Nano module), $72.2 \%$ of cylinder heads are capable of being uniquely identifiable by the intelligent RTI. It should be noted that only 2 of these locations achieved less than $50 \%$ read success rate (number of successful reads / attempts), positions C3 at $43.33 \%$ and C4 at $36.66 \%$ both on layer 2 . In conclusion, it shows that it is viable to utilise commercial on-metal RFID tags for the unique identification of cylinder heads when placed within an intelligent RTI. However, with the current RFID setup it was not possible to identify $100 \%$ of components placed within an RTI. Despite this, the use of RFID tags on components still provides the intelligent RTI with contextual information, such as that there are components present. Despite not achieving a $100 \%$ identification rate, the unique RFID tagging of cylinder heads provides the added benefit of being capable to integrate with machining processes, quality control tests and assembly lines providing an additional level of traceability and control.

\section{3 smaRTI Decision}

As previously discussed a smart container's decision making ability can be split by its capacity to make decisions not only for itself but decisions for the component assembled on or inside it.

The smaRTI has been designed to allow decisions such as when it requires repair based on monitored experiences, i.e. detection of collision and knowledge of the time elapsed between last inspections. A fleet of smarRTIs would allow much more in terms transport orchestration (i.e. logistics 4.0; flexible scheduling, optimisation of processes and visibility [80]) however these high level decisions and data analytics are not the focus of this paper. Similarly the smaRTI would be able to determine if a held item requires inspection. Identification of an item allows a unique history of environmental conditions and other physical experiences to be compiled for further analytics, for example certain components if left outside in particular environmental conditions could be more likely to corrode and require inspection before use on an assembly line.

\section{Conclusion}

The research and development of a hardware and software platform to support the implementation of intelligent containers has been presented within this paper. Where previous research has been discussed within the freight industry and cold food supply chain, this research has implemented a proof of concept device for creating intelligent RTIs that have the ability to interact with intelligent components, its environment and an intelligent manufacturing system within the harsh automotive manufacturing domain. Through the identification of intelligent product definitions and requirements, a CPS reference architecture has been presented that identifies the need to be adaptable, scalable, extendable and secure. The instantiation of the CPS reference architecture has been presented in the form of an MQTT publish and subscribe service bus integrated within a series of Node-Red services for the rapid deployment of intelligent container services and user interfaces for investigation purposes. 
Through the implementation of the smaRTI hardware, investigations for the feasibility of intelligent container context services were carried out. It was shown that through the correct implementation of available UHF RFID tags for use on metal, that an engine cylinder head can be effectively read in the laboratory at up to $3.8 \mathrm{~m}$ distance. This correlates with a $72.7 \%$ identification rate of cylinder heads when stacked (up to three levels) into an intelligent container. It has also been shown that through the use of embedded sensors (i.e. accelerometer, gyroscope, magnetometer, altimeter, temperature and humidity) that a number of logistical handling features can be identified, such as the occurrence of lifting and lowering operations for RTI storage, the occurrences of RTI collisions and identifying turns during movement to aid in location determination and route traceability. These contextual pieces of information provide a new level of traceability granularity within the manufacturing domain, which not only provides the unique traceability information of individual components, but provides a full detailed monitoring of its history. Included in the information is the potential for metrics that are representative of manufacturing system performance (i.e. time taken to assembly, RTI utilisation and dwell times) but also additional logistical handling performance (i.e. collision rates, temperature and humidity excursions and component locations). This capability will give firms the tools and empirical evidence to make process improvements, achieve better quality control, improve product quality and ultimately reduce the risks associated with component logistics, traceability and control.

\section{Future Work}

Several areas for future work have been identified within this research to promote further the need for intelligent containers and accompanying CPS services. With the integration of intelligent containers and intelligent components there is a significant increase in the granularity of traceability information, including environmental and physical experiences. This research has yet to consider what effects that this could have on a manufacturing firm with regards to production planning, quality control, process adherence and financial savings. It is also identified that there are many other types of RTIs within industry, such as in the cold food or consumer goods supply chains, that have different handling processes and concerns with RTI management that could be investigated with the smaRTI hardware and software platform. Whilst this research has presented a number of feasibility studies for the determination of RTI context, it has not considered what effect the identified events have on the components being transported. For example, in the event of a collisions, to what extent do collision forces impact upon the quality of the components, i.e. what level of force / temperature / humidity would damage a cylinder head when being transported.

\section{Acknowledgements}

Funding: The authors wish to express their gratitude to the industrial and academic collaborators of the Al2M Project (Adaptive Informatics for Intelligent Manufacturing). The EPSRC Grant award No. EP/K014137/1 supported this work financially. 


\section{References}

[1] Q. Zhang, A. Segerstedt, Y.-C. Tsao, and B. Liu, "Returnable packaging management in automotive parts logistics: Dedicated mode and shared mode," Int. J. Prod. Econ., vol. 168, pp. 234-244, 2015.

[2] L. Thoroe, A. Melski, and M. Schumann, "The impact of RFID on management of returnable containers," Electron. Mark., 2009.

[3] S. D. P. Flapper, “One-way or reusable distribution items?” 1995.

[4] IC-RTI, "Reusable transport items (RTI) - organisational recommendations," 2003.

[5] M. Ritamaki and A. Ruhanen, "Embedded passive UHF RFID seal tag for metallic returnable transit items," in 2010 IEEE International Conference on RFID (IEEE RFID 2010), 2010, pp. 152-157.

[6] A. Ilic, J. W. P. Ng, P. Bowman, and T. Staake, "The value of RFID for RTI management," Electron. Mark., vol. 19, no. 2-3, pp. 125-135, Jul. 2009.

[7] C. E. Witt, "Transport Packaging: Neat and Clean or Down and Dirty," Material Handling Engineering, 1999. .

[8] D. Hellström and O. Johansson, "The impact of control strategies on the management of returnable transport items," Transp. Res. Part E Logist. Transp. Rev., vol. 46, no. 6, pp. 1128-1139, Nov. 2010.

[9] L. Breen, "Give me back my empties or else! A preliminary analysis of customer compliance in reverse logistics practices (UK)," Manag. Res. News, vol. 29, no. 9, pp. 532-551, 2006.

[10] O. Johansson and D. Hellström, "The effect of asset visibility on managing returnable transport items," Int. J. Phys. Distrib. Logist. Manag., vol. 37, no. 10, pp. 799-815, Nov. 2007.

[11] BRIDGE: Building Radio frequency IDentification for the Global Environment, "Returnable Transport Items: the market for EPCglobal applications," www.bridge-project.eu, 2007. .

[12] D. Hellström, "The cost and process of implementing RFID technology to manage and control returnable transport items," Int. J. Logist. Res. Appl., vol. 12, no. 1, pp. 1-21, Feb. 2009.

[13] R. Carrasco-gallego and E. Ponce-cueto, "A management model for closed-loop supply chains of reusable articles : proposing solutions," Int. Conf. Ind. Eng. Ind. Manag., vol. 4, no. c, pp. 1795-1804, 2010.

[14] R. R. Young, P. F. Swan, and R. H. Burn, "Private Railcar Fleet Operations: The Problem of Excessive Customer Holding Time in the Chemicals and Plastics Industries," Transp. J., vol. 42, no. 1, p. 51, 2002.

[15] B. Konsynski and S. Vitzthum, "CHEP: The Net of Things," in ICIS, 2007, vol. 22, no. 26.

[16] R. Carrasco-Gallego, E. Ponce-Cueto, and R. Dekker, “A framework for closed-loop supply chains of reusable articles," no. August, pp. 1-40, 2010.

[17] M. Holmqvist and G. Stefansson, "'SMART GOODS'AND MOBILE RFID A CASE WITH INNOVATION FROM VOLVO," J. Bus. Logist., 2006.

[18] D. McFarlane, S. Sarma, J. L. Chirn, C. . Wong, and K. Ashton, “Auto ID systems and intelligent manufacturing control," Eng. Appl. Artif. Intell., vol. 16, no. 4, pp. 365-376, Jun. 2003.

[19] S. Bussmann and K. Schild, "Self-organizing manufacturing control: an industrial application of agent technology," in Proceedings Fourth International Conference on MultiAgent Systems, pp. 87-94.

[20] C. Y. Wong, D. McFarlane, A. Ahmad Zaharudin, and V. Agarwal, "The intelligent product driven supply chain," in IEEE International Conference on Systems, Man and Cybernetics, 2002, vol. vol.4, p. 6.

[21] M. Rönkkö, M. Kärkkäinen, and J. Holmström, "Benefits of an item-centric enterprise-data model in logistics services: A case study," Comput. Ind., vol. 58, no. 8-9, pp. 814-822, Dec. 2007.

[22] M. Kärkkäinen, T. Ala-Risku, and K. Främling, "The product centric approach: a solution to supply network information management problems?,” Comput. Ind., vol. 52, no. 2, pp. 147-159, 2003. 
[23] J. Barbosa, P. Leitão, D. Trentesaux, A. W. Colombo, and S. Karnouskos, “Cross Benefits from Cyber-Physical Systems and Intelligent Products for Future Smart Industries Cross Benefits from Cyber-Physical Systems and Intelligent Products for Future Smart Industries," IEEE, no. July, pp. 504-509, Jul. 2016.

[24] D. McFarlane, S. Sarma, and J. Chirn, “Auto ID systems and intelligent manufacturing control," ... Appl. Artif. ..., vol. 16, no. 4, pp. 365-376, Jun. 2003.

[25] O. Ventä, "Intelligent products and systems," Technol. Theme-Final Report. VTT, Espoo VTT Publ., vol. $304,2007$.

[26] G. G. Meyer, K. Främling, and J. Holmström, "Intelligent Products: A survey," Comput. Ind., vol. 60, no. 3, pp. 137-148, Apr. 2009.

[27] W. Zhou, S. Piramuthu, F. Chu, and C. Chu, "RFID-enabled flexible warehousing," Decis. Support Syst., vol. 98, pp. 99-112, Jun. 2017.

[28] Su Jin Kim, Guofeng Deng, S. K. S. Gupta, and M. Murphy-Hoye, "Intelligent networked containers for enhancing global supply chain security and enabling new commercial value," in $20083 \mathrm{rd}$ International Conference on Communication Systems Software and Middleware and Workshops (COMSWARE '08), 2008, pp. 662-669.

[29] P. Ruckebusch, J. Hoebeke, E. De Poorter, and I. Moerman, "Smart container monitoring using custom-made WSN technology: from business case to prototype," EURASIP J. Wirel. Commun. Netw., vol. 2018, no. 1, p. 16, Dec. 2018.

[30] G. La Scalia, A. Nasca, O. Corona, L. Settanni, and R. Micale, “An Innovative Shelf Life Model Based on Smart Logistic Unit for an Efficient Management of the Perishable Food Supply Chain," J. Food Process Eng., vol. 40, no. 1, p. e12311, Feb. 2017.

[31] W. Lang, R. Jedermann, D. Mrugala, A. Jabbari, B. Krieg-Brückner, and K. Schill, “The 'Intelligent Container'-A Cognitive Sensor Network for Transport Management," IEEE Sens. J., vol. 11, no. 3, pp. 688-698, Mar. 2011.

[32] Mersk, "Maersk - Remote Container Monitoring (RCM)." [Online]. Available: https://www.maersk.com/en/solutions/shipping/remote-container-management. [Accessed: 20-Mar-2019].

[33] Bosch, "Bosch and SAP connect forklifts and goods." [Online]. Available: https://www.boschpresse.de/pressportal/de/en/bosch-and-sap-connect-forklifts-and-goods-65092.html. [Accessed: 20-Mar-2019].

[34] Zenotrack, "Zenoway." [Online]. Available: https://www.zenotrack.com/en/. [Accessed: 20-Mar-2019].

[35] Vero Solutions, "Vero Solutions - Tracking Reusable Transport Items." [Online]. Available: https://vero.solutions/solutions/tracking-reusable-transport-items/. [Accessed: 19-Mar-2019].

[36] TrackX, "TrackX - Transportation \& Logistics Industry." [Online]. Available: http://trackx.com/industriestransportation-logistics/. [Accessed: 19-Mar-2019].

[37] IMSAS, "The intelligent container." [Online]. Available: http://www.intelligentcontainer.com/en/home.html. [Accessed: 19-Mar-2019].

[38] C. Y. Wong, D. McFarlane, A. Ahmad Zaharudin, and V. Agarwal, "The intelligent product driven supply chain," in IEEE International Conference on Systems, Man and Cybernetics, vol. vol.4, p. 6.

[39] A. K. Parlikad and D. McFarlane, "RFID-based product information in end-of-life decision making," Control Eng. Pract., vol. 15, no. 11, pp. 1348-1363, Nov. 2007.

[40] D. McFarlane, V. Giannikas, A. C. Y. Wong, and M. Harrison, "Product intelligence in industrial control: Theory and practice," Annu. Rev. Control, vol. 37, no. 1, pp. 69-88, Apr. 2013.

[41] G. G. Meyer, P. Buijs, N. B. Szirbik, and J. C. (Hans) Wortmann, "Intelligent products for enhancing the utilization of tracking technology in transportation," Int. J. Oper. Prod. Manag., vol. 34, no. 4, pp. 422-446, Apr. 2014.

[42] J. Shi, J. Wan, H. Yan, and H. Suo, "A survey of Cyber-Physical Systems," in 2011 International Conference on Wireless Communications and Signal Processing (WCSP), 2011, pp. 1-6.

[43] S. A. Seshia, S. Hu, W. Li, and Q. Zhu, “Design Automation of Cyber-Physical Systems: Challenges, Advances, and Opportunities," IEEE Trans. Comput. Des. Integr. Circuits Syst., vol. 36, no. 9, pp. 1421-1434, 2017. 
[44] V. Gunes, S. Peter, T. Givargis, and F. Vahid, "A survey on concepts, applications, and challenges in cyberphysical systems," KSII Trans. Internet Inf. Syst., vol. 8, no. 12, pp. 4242-4268, Dec. 2014.

[45] L. Esterle and R. Grosu, "Cyber-physical systems: challenge of the 21st century," Elektrotechnik und Informationstechnik, vol. 133, no. 7, pp. 299-303, 2016.

[46] VID/VDE, “Reference Architecture Model Industrie 4.0 (RAMI4.0)," Igarss 2014, no. 1, p. $28,2015$.

[47] OASIS, "OASIS - Advancing open standards for the information society." .

[48] M. P. Papazoglou, W.-J. Van Den Heuvel, M. P. Papazoglou, and W.-J. Van Den Heuvel, "Service oriented architectures: approaches, technologies and research issues," VLDB J., vol. 16, pp. 389-415, 2007.

[49] D. M. Lambert and M. C. Cooper, "Issues in Supply Chain Management," Ind. Mark. Manag., vol. 29, no. 1, pp. 65-83, Jan. 2000.

[50] G. M. Siddesh, G. C. Deka, K. G. Srinivasa, and L. M. Patnaik, Cyber-physical systems : a computational perspective. .

[51] P. Wang, Y. Xiang, and S. H. Zhang, “Cyber-Physical System Components Composition Analysis and Formal Verification Based on Service-Oriented Architecture," in 2012 IEEE Ninth International Conference on e-Business Engineering, 2012, pp. 327-332.

[52] S. H. Ahmed, G. Kim, and D. Kim, "Cyber Physical System: Architecture, applications and research challenges," in 2013 IFIP Wireless Days (WD), 2013, pp. 1-5.

[53] A. W. Colombo, T. Bangemann, S. Karnouskos, J. Delsing, P. Stluka, R. Harrison, F. Jammes, and J. Lastra, Industrial Cloud-Based Cyber-Physical Systems. Cham: Springer International Publishing, 2014.

[54] T. Berners-Lee, R. Fielding, and L. Masinter, "Uniform Resource Identifier (URI): Generic Syntax," Jan. 2005.

[55] D. Segura-Velandia, A. Neal, P. Goodall, P. Conway, and A. West, "Industrie 4.0 implementations in the automotive industry," in Advances in Transdisciplinary Engineering, 2016, vol. 3, pp. 319-324.

[56] B. Segall and D. Arnold, "Elvin has left the building: A publish/subscribe notification service with quenching."

[57] “OASIS Message Queuing Telemetry Transport (MQTT) TC | OASIS.” [Online]. Available: https://www.oasisopen.org/committees/tc_home.php?wg_abbrev=mqtt. [Accessed: 05-Oct-2018].

[58] V. Arya, J. Hazra, P. Kodeswaran, D. Seetharam, N. Banerjee, and S. Kalyanaraman, “CPS-Net: In-network aggregation for synchrophasor applications," in 2011 Third International Conference on Communication Systems and Networks (COMSNETS 2011), 2011, pp. 1-8.

[59] H.-C. Jo and H.-W. Jin, "Adaptive Periodic Communication over MQTT for Large-Scale Cyber-Physical Systems," in 2015 IEEE 3rd International Conference on Cyber-Physical Systems, Networks, and Applications, 2015, pp. 6669.

[60] T. Magalhães, I. C. Oliveira, and J. M. Fernandes, "Message based integration in Cyber-Physical System: firefighters in the field," 12th EAl Int. Conf. Mob. Ubiquitous Syst. Comput. Netw. Serv., pp. 0-1, 2015.

[61] K. Holm, “Using MQTT Protocol Advantages Over HTTP in Mobile Application Development," IBM Developer Works, 2012. .

[62] S. Nicholas, "Power Profiling: HTTPS Long Polling vs. MQTT with SSL, on Android," 2012. .

[63] R. A. Light, "Mosquitto : server and client implementation of the MQTT protocol," J. Open Source Softw., vol. 2, no. May, pp. 10-11, May 2017.

[64] JS Foundation, “Node-RED.” 2016.

[65] Node.js, “Node.js.” 2017.

[66] S. J. Preece, J. Y. Goulermas, L. P. J. Kenney, and D. Howard, "A comparison of feature extraction methods for the classification of dynamic activities from accelerometer data," IEEE Trans. Biomed. Eng., vol. 56, no. 3, pp. 
871-879, Mar. 2009.

[67] M. Zhang and A. Sawchuk, "A Feature Selection-Based Framework for Human Activity Recognition Using Wearable Multimodal Sensors," in Proceedings of the 6th International ICST Conference on Body Area Networks, 2011, pp. 92-98.

[68] J. Wan, M. Chen, F. Xia, L. Di, and K. Zhou, "From machine-to-machine communications towards cyber-physical systems," Comput. Sci. Inf. Syst., vol. 10, no. 3, pp. 1105-1128, Jun. 2013.

[69] A. Musa, A. Gunasekaran, and Y. Yusuf, "Supply chain product visibility: Methods, systems and impacts," Expert Syst. Appl., vol. 41, no. 1, pp. 176-194, 2014.

[70] V. P. Nighot, S. M. Lambor, and S. M. Joshi, "Efficient battery management in wireless sensor node: Review paper," 2014 Elev. Int. Conf. Wirel. Opt. Commun. Networks, pp. 1-5, Sep. 2014.

[71] M. Magno, L. Benini, R. Giuffrida, S. Leonardi, and D. Brunelli, “A portable hybrid hydrogen fuel cell-battery power unit for wireless sensor network," in 2014 International Symposium on Power Electronics, Electrical Drives, Automation and Motion, SPEEDAM 2014, 2014, pp. 173-178.

[72] Freescale Semiconductor, “MPL3115A2, I2C Precision Altimeter," 2015.

[73] J. Parviainen, J. Kantola, and J. Collin, "Differential barometry in personal navigation," in 2008 IEEE/ION Position, Location and Navigation Symposium, 2008, pp. 148-152.

[74] F. Gustafsson and F. Gunnarsson, "Positioning using time-difference of arrival measurements," 2003 IEEE Int. Conf. Acoust. Speech, Signal Process. 2003. Proceedings. (ICASSP'03)., vol. 6, pp. 553-556, 2003.

[75] X. Zhong, J. Wang, and L. Mei, “A Survey of Indoor Location Algorithms Based on AOA," DEStech Trans. Eng. Technol. Res., vol. 0, no. Iceta, pp. 273-278, Apr. 2016.

[76] X. Zhu and Y. Feng, "RSSI-based Algorithm for Indoor Localization," Commun. Netw., vol. 05, no. 02, pp. 37-42, 2013.

[77] Y. S. Shweta Singh, Ravi Shakya, "Localization Techniques in Wireless Sensor Networks," Int. J. Distrib., vol. 6, no. 1, pp. 844-850, 2015.

[78] L. Koping, M. Grzegorzek, and F. Deinzer, "Probabilistic Step and Turn Detection in Indoor Localization," in IET Conference on Data Fusion \& Target Tracking 2014: Algorithms and Applications, 2014, p. 2.2-2.2.

[79] A. Broquetas, A. Comerón, A. Gelonch, J. Fuertes, J. Castro, D. Felip, M. López, and J. Pulido, "Track Detection in Railway Sidings Based on MEMS Gyroscope Sensors," Sensors, vol. 12, no. 12, pp. 16228-16249, Nov. 2012.

[80] N. Schmidtke, F. Behrendt, L. Thater, and S. Meixner, "Technical potentials and challenges within internal logistics 4.0," in 2018 4th International Conference on Logistics Operations Management (GOL), 2018, pp. 1-10. 